\title{
A critical review of the literature on comfort of hearing protection devices: Definition of comfort and identification of its main attributes for earplug types
}

Olivier Doutres $^{\mathrm{a} *}$ and Franck Sgard ${ }^{\mathrm{b}}$, Jonathan Terroir ${ }^{\mathrm{c}}$, Nellie Perrin ${ }^{\mathrm{c}}$, Caroline Jolly $^{\mathrm{b}}$, Chantal Gauvin ${ }^{\mathrm{b}}$, Alessia Negrini ${ }^{\mathrm{b}}$

${ }^{a}$ Department of Mechanical Engineering, École de Technologie Supérieure, ÉTS, 1100 rue Notre-Dame Ouest, Montréal, Québec, Canada, H3C 1K3

${ }^{b}$ Institut de recherche Robert-Sauvé en santé et en sécurité du travail, IRSST, 505 Boulevard de Maisonneuve Ouest, Montréal, Québec, Canada, H3A 3C2

'Institut national de recherche et de Sécurité, INRS, 1 rue du MORVAN, 54500 Vandoeuvre-lès-Nancy, France

Corresponding author: olivier.doutres@etsmtl.ca

\begin{abstract}
:
Objective: This paper presents a comprehensive literature review of past works addressing Hearing Protection Devices (HPD) comfort and to put them into perspective regarding a proposed holistic multidimensional construct of HPD comfort. Design: Literature review. Study samples: Documents were hand searched and Internet searched using "PubMed”, “Web of Science”, “Google Scholar”, “ProQuest Dissertations and Theses Professional”, "Scopus" or "Google" search engines. While comfort constructs and measurement methods are reviewed for both earplugs and earmuff types, results and analyses are provided for the earplug type only. Results: This paper proposed a multidimensional construct of HPD comfort based on four dimensions: physical, functional, acoustical and psychological. Seen through the prism of the proposed holistic construct of HPD comfort, the main comfort attributes of earplugs have been identified for each comfort dimension. Conclusions: The observed lack of consensus on the definition of HPD comfort in the scientific community makes it difficult to prioritize the importance of comfort attributes yet necessary for future design of comfortable earplugs.
\end{abstract}

International Journal of Audiology, https://doi.org/10.1080/14992027.2019.1646930

This is an Accepted Manuscript of an article published by Taylor \& Francis in International Journal of Audiology on 31 Jul 2019 , available online: http://www.tandfonline.com/10.1080/14992027.2019.1646930. 
Keywords: Earplug, hearing protection device, comfort, questionnaire, literature review.

\section{Introduction}

Hearing Protection Devices (HPDs), such as earplugs or earmuffs, are widely used means for reducing the noise exposure. However, this noise control solution is sometimes considered to insufficiently protect the workers from noise induced hearing loss (Groenewold et al. 2014). The main reasons explaining this apparent non-efficiency are also well known (Berger and Voix 2018): the protectors are not worn at all or not worn consistently and/or correctly. Field studies report that between 3\% and $74 \%$ of workers exposed to high noise level never use HPDs even if they are provided by employers as mandated by law (Arezes and Miguel 2005a; Arezes and Miguel 2005b; Davis and Sieber 2002; Hong, Lusk, and Ronis 2005; McCullagh, Ronis, and Lusk 2010; Tak, Davis, and Calvert 2009; Tantranont and Codchanak 2017). For workers wearing HPDs, multiple field studies found a low level of HPD use ranging between $20 \%$ and $50 \%$ of the time exposed to high noise levels (Abel et al. 1985; Arezes and Miguel 2005a; Arezes and Miguel 2005b; Edelson et al. 2009; Lusk, Kerr, and Kauffman 1998; Melamed, Rabinowitz, and Green 1994; Melamed et al. 1996; Neitzel and Seixas 2005; Seixas et al. 2011). Insufficient wearing time has important consequences on the effective protection of exposed workers, with HPD efficiency decreasing rapidly if not worn during all the exposure time (Canadian Centre for Occupational Health and Safety 2017). An improper wearing of HPDs can also affect their efficiency. A poor fit between the HPD and the body (inside the earcanal for earplugs and over the ear for earmuffs) creates acoustic leaks affecting HPD efficiency. In order to account for this effect when selecting the HPD, the National Institute for Occupational Safety and Health (NIOSH) recommends estimating the effective attenuation of the protector directly on site when the worker tries and fits different HPDs (Berger et al. 2011) or to decrease the labeled Noise Reduction Rating (NRR) (Canadian Centre for Occupational Health and Safety 2017; Canadian Standards Association 2014). It is thus essential to consistently and correctly use the HPD since the provided protection falls very quickly when it is removed intermittently and/or not worn properly (Arezes and Miguel 2005b; Arezes and Miguel 2006; Berger and Voix 2018). 
Factors causing HPD bad use or non-use are various. Numerous studies (beyond the scope of this paper) investigate them thoroughly based on field subjective test campaigns and behavioral models. Their goal is to identify the main factors affecting HPD use and to develop effective interventions to promote HPD use. To no one's surprise, comfort is found to be a strong factor influencing HPD use (Bockstael, De Bruyne, and Vinck 2011; Costa and Arezes 2013; Cramer et al. 2017; Edelson et al. 2009; Hong, Chin, and Ronis 2013; Kushnir et al. 2006; McCullagh et al. 2016; Morata et al. 2001; Patel et al. 2001; Reddy et al. 2012; M. R. Stephenson 2009; M. R. Stephenson et al. 2011; Svensson et al. 2004) and numerous authors conclude that the promotion of HPD use should be based, among others, on the removal of barriers of use, for example, by offering workers more comfortable HPDs (Arezes and Miguel 2005a; Bockstael, De Bruyne, and Vinck 2011; Bockstael et al. 2012; Canetto 2009; Groenewold et al. 2014; Hong, Chin, and Ronis 2013; Melamed et al. 1996; Svensson et al. 2004). However, this leads to the following questions: (i) How is comfort defined in the framework of HPD use?; (ii) How is HPD comfort evaluated?; (iii) What are the identified sources of (dis)comfort associated with the use of an HPD? The present literature review aims at summarizing how these questions are usually approached. The first two questions are tackled for HPDs in general (earmuff and earplug types). The various constructs of HPD comfort found in the literature leads us to propose a more holistic multidimensional construct based on four dimensions: physical, functional, acoustical and psychological. The last question is then dealt with in a last section through the prism of the proposed HPD comfort construct while focusing on earplugs.

\section{Concepts and constructs of HPD comfort}

In this paper, the definitions of "concept" and "construct” are taken from Branson and Sweeney (1991): concept is an abstraction formed by generalizations from particulars ( $a$ mental image, idea), and construct is a concept deliberately invented for scientific purposes, that can be operationalized for measurement in a given study.

\section{Concepts and constructs found in the literature}

In the literature dedicated to HPD, the word "comfort” is generally employed to designate all aspects related to the mechanical contact between the HPD and the outer ear for earplugs 
or the circumaural and pinna for earmuffs (called "touch related non-acoustical" aspects in (Bockstael et al. 2012)) leading to physical sensations which may prevent a correct and consistent HPD use (Abel 2008; Behar and Desormeaux 1986; Behar and Jackson 1987; Bhattacharya, Tripathi, and Kashyap 1993; Bockstael, De Bruyne, and Vinck 2011; Bockstael, Keppler, and Botteldooren 2015; Broughton 1995; Byrne et al. 2011; Canetto 2009; Casali et al. 1987; Damongeot 1977; Damongeot et al. 1982; Du, Homma, and Saunders 2008; Edelson et al. 2009; Epps and Casali 1985; Flugrath and Tuberville 1972; Grenell 1988; Groenewold et al. 2014; Ivergård and McK. Nicholl 1976; Ivarsson, Toremalm, and Brühl 1990; Kusy 1991; Kusy 1996; Mauney and Casali 1990; Melamed et al. 1996; Morata et al. 2001; Mozo, Murphy, and Ribera 1995; Park and Casali 1991; Patel et al. 2001; Samelli et al. 2018; Smith, Monaco, and Lusk 2014; Spomer et al. 2017; M. R. Stephenson 2009; C. M. Stephenson and Stephenson 2011; M. R. Stephenson et al. 2011; Stork and Gasaway 1977; Sweetland 1983; Tantranont and Codchanak 2017; Tisserand and Krawsky 1972; Tufts et al. 2011; Wheeler and Glorig 1956; Zwislocki 1958). The construct of comfort is thus characterized by one or multiple attributes related to user perception resulting from mechanical and thermal interactions: e.g., "mechanical pressure” exerted by the HPD on the body, "pain”, "irritation”, "friction”, "weight”, "size”, "temperature", "heating and sweating" of the skin induced by mechanical contact. Depending on the studies, this construct of comfort also accounts for functional aspects of the HPD and characterized by one or multiple attributes such as: "ease of insertion, "ease of fit”, "stability" (maintain in position), "ease of removal”.

Because of this restricted construct of comfort, some authors also interested in understanding HPD non-use investigate additional constructs such as "general comfort", "preference”, "general preference”, “acceptance”, “wearability”, "general wearability” or "convenience” (Casali et al. 1987; Epps and Casali 1985; Flugrath and Tuberville 1972; Grenell 1988; Park and Casali 1991; Sweetland 1983; Stork and Gasaway 1977; Samelli et al. 2018; Brown-Rothwell 1986) which accounts for more attributes related to functional aspects (e.g., "ease of insertion”, “ease of use”, "stability”) and/or psychological aspects (e.g., “acceptability”, “attractiveness”) (Grenell 1988; Park and Casali 1991). It is worth noting that, even among studies sharing this construct of comfort (restricted to mechanical 
aspects), confusion and ambiguity may arise since the attributes characterizing it can vary. For example, some attributes may specifically be not included (e.g., "ease of insertion" in (Casali et al. 1987; Du, Homma, and Saunders 2008; Epps and Casali 1985; Park and Casali 1991), "stability" in (Du, Homma, and Saunders 2008; Park and Casali 1991)) or in most cases, the researchers mention which attributes are accounted for in their construct but not those which are not and why. The observed lack of consensus on the definition of comfort in the scientific community may generate a bias in its assessment. Furthermore, one can also easily extrapolate and assume another possible bias if the participant's own concept of comfort is different from the construct proposed by the research team. Casali et al. (1987) mention the incompleteness of the construct of comfort (restricted to mechanical aspects in their works) which is probably too restrictive for subjective HPD assessment. Indeed, Bockstael et al. (2012) confirm that the concept of comfort as perceived by workers is mainly controlled by mechanical aspects but that acoustical ones can also play a significant role. The acoustical aspects are usually related to the perception of external noises and characterized by attributes such as "speech intelligibility", "capacity in hearing useful signals" or "capacity in hearing warning signals".

Only few studies consider the HPD comfort in a more holistic perspective (Arezes, Abelenda, and Braga 2008; Brown-Rothwell 1986; Gonçalves et al. 2015; Hsu et al. 2004; Lhuede 1980). Hsu et al. (2004) consider acoustical and non-acoustical comfort attributes such as: "having difficulties in conversation”, "feeling itchy”, "acoustic change”, "interfere with work", "discomfort due to hard contact part”. Brown-Rothwell (1986) investigates HPD global comfort based on four dimensions: "convenience", "comfort", "communication" and "appearance". Comfort is thus used at the same time as a construct (also characterized by the word "acceptance" in their work and others) and as one of its dimension. More particularly, the construct of comfort proposed by the author is composed of three different dimensions: the "sensation", referring to physical attributes, the "satisfaction" concerning psychological attributes and the "tolerance" including compound attributes. Psychological comfort is rarely considered in the studies focused on HPDs comfort. It can nevertheless be found in (Nordin 1968) (cited in (Ivergård and McK. Nicholl 1976; Tourigny 1980)) and (Brown-Rothwell 1986) but the lack of information 
about this dimension and its definition prevent any specific analysis. However, Terroir et al. (2017) mention that this construct of "psychological comfort" refers to the well-being of the HPD user and cannot be a priori ignored, since it is an integral part of the concept of comfort and how it is perceived and evaluated.

Finally, it is worth mentioning that the construct of comfort used by the researchers depends on the final goal of the in-ear or over-ear device. Indeed, in the case of hearing aids, the sound quality is one of the most important factors to overall satisfaction and (dis)comfort is partly or completely characterized by acoustical attributes such as the “occlusion effect” and “acoustic feedback” (Branda 2012; French-Saint George and BarrHamilton 1978; Furstenberg, Gordon, and Baccaro 1988; Mackenzie, Browning, and McClymont 1989). In the same way, acoustical attributes are included in the construct of comfort in studies dealing with hearing protectors dedicated to musicians (Bernier 2013) or workers for which spatial acoustic information is of upmost importance and should not be altered (e.g., military or law enforcement) (Brown et al. 2015; Ribera et al. 1995).

It has been shown that a wide variety of comfort constructs, more or less complete and thus requiring more or less constructs for understanding HPD non-use, can be found in the literature depending on the research team performing the comfort analysis and the type of HPD investigated. Unfortunately, this could hinder the combination and analysis of data coming out from different studies and thus the proposal of interesting outcomes on HPD comfort for research and occupational health practice. To reach this goal, a holistic construct of comfort for HPDs should be proposed and find consensus.

Indeed, due to its subjective nature and to the large number of factors that can be taken into account, the definition of comfort is a complex task and has been debated for many years (Davis 2008; Kolcaba and Kolcaba 1991; Kuijt-Evers et al. 2004; Pearson 2009). Comfort can be related to various attributes, but still remains difficult to define and characterize with objective measures since it is, beyond dispute, feelings and emotions that are subjective in nature (De Looze, Kuijt-Evers, and Van DieëN 2003). As an example of this complexity, Branson and Sweeney (1991) propose an interesting definition related to the comfort of clothes (also cited in (Davis 2008)): a state of satisfaction indicating physiological, 
psychological and physical balance among a person, his/her clothes and his/her environment. This sums up quite well the interactions that may exist between the user, his/her equipment and his/her environment in a more general way.

\section{Proposed construct of HPD comfort}

In this paper, we propose a holistic construct of comfort for HPDs (and more generally for all types of "ear devices" : in-ear, on-ear and over-the-ear devices) adapted from the definition of comfort of Branson and Sweeney (1991). The word comfort is thus used as a global perception characterizing a balance between the physical, functional, acoustical, and psychological factors associated with the relationship between the user and his/her HPD in a context of specified use (here, a given work environment). The proposed construct for HPD comfort is multidimensional and includes the following four dimensions: (1) the "physical" dimension related to the user perception resulting from biomechanical and thermal interactions; (2) the "functional" dimension, which corresponds to the practical acceptability of HPDs that refers to the usability, efficiency and usefulness of the HPD; (3) the "acoustical" dimension related to the modification of the perception of both external and internal noises; (4) the "psychological" dimension, which refers to the well-being of the user (assessed for example through trust, habituation and satisfaction). Acoustics being a branch of physics, attributes belonging to the acoustical dimension should rigorously be included in the physical one. However, because of the great importance of the acoustical dimension for HPDs (but also for all types of ear devices in general), the authors decided deliberately to separate the two and put a special emphasis on acoustical comfort attributes.

In the two following sections, past works on the evaluation of HPD comfort seen through the prism of the proposed multidimensional construct of comfort are reviewed. Even if this paper focuses on earplugs, important research methodologies on earmuff comfort are also presented in the following section. 


\section{Evaluation of HPD comfort}

\section{Methods and test protocol}

Numerous studies have been carried out in the past in order to quantify the comfort of HPDs as well as the preferences of the users associated with the wearing of HPDs (earplugs and earmuffs) (Arezes, Abelenda, and Braga 2008; Arezes and Miguel 2002; Baker, Lee, and Mayfield 2010; Behar, Segu, and Russo 2014; Behar and Desormeaux 1986; Behar and Jackson 1987; Bhattacharya, Tripathi, and Kashyap 1993; Bockstael et al. 2012; Brown-Rothwell 1986; Byrne et al. 2011; Casali 1992; Casali et al. 1987; Casali and Lam 1986; Casali and Park 1990; Damongeot 1977; Damongeot et al. 1982; Davis 2008; Davis et al. 2011; Davis and Shaw 2016; Gerges 2012; Grenell 1988; Hsu et al. 2004; Ivarsson, Toremalm, and Brühl 1990; Ivergård and McK. Nicholl 1976; Kusy 1991; Mozo, Murphy, and Ribera 1995; Murphy et al. 2007; Norris et al. 2011; Park and Casali 1991; Schulz et al. 1983; C. M. Stephenson and Stephenson 2011; Sviech et al. 2013; Sweetland 1983; Tisserand and Krawsky 1972; Zwislocki 1958). All these studies obtain data from selfreport questionnaires assessing human perceptions, attitudes, feelings and beliefs. These studies can nevertheless be differentiated by: (i) the proposed construct of HPD comfort, (ii) the test environment (in laboratory or on site), (iii) the type and number of HPDs investigated, (iv) the wearing time, (v) the experience of participant with HPD use, (vi) the number of participants, (vii) the test protocol, (viii) the questionnaires and type of rating scales, (ix) the comfort attributes investigated and conclusions about the most important ones and (x) the construction of an indicator of the global perception of comfort. The last three items are detailed in the next sub-sections while the first ones will be covered in a forthcoming paper.

\section{Questionnaires}

Questionnaires are used to assess the characteristics of the participants wearing HPDs (e.g., age, sex), of their work environment (e.g., perceived noise level, time of exposure) and the importance of comfort attributes associated with the wearing of HPDs. From the literature review, it is possible to identify three groups of questionnaires depending on the phase of the research at which they are administered. 
The first group of questionnaires is administered at the beginning of the test campaign and allows for assessing basic information about the participants, their work environment (for field measurements) and their relation to the HPDs. These characteristics are also referred to as modifying factors in studies interested in modeling workers' behavior toward HPD use (Hong, Chin, and Ronis 2013; Lusk et al. 1994; Lusk, Ronis, and Hogan 1997). Some examples of these modifying factors requested in existing questionnaires are: participants’ age, sex, educational level and daily experience with the wearing of earplug (e.g., preference between earmuffs or earplugs, average wearing time) (Du, Homma, and Saunders 2008; Hsu et al. 2004; Laitinen and Poulsen 2008; Sviech et al. 2013; Sweetland 1983), perceived usefulness and good understanding of the instructions provided by the manufacturers about how the HPD should be worn (Ivergård and McK. Nicholl 1976), number of years working in the company and number or years participating in the hearing preservation program offered by the company (Gonçalves et al. 2015), beliefs and attitudes about work in noise and the wearing of HPDs (Davis and Shaw 2016) (the NIOSH reference questionnaire is provided in Appendix 1 of ref. (C. M. Stephenson and Stephenson 2011)) and finally possible noisy recreations and the use of over-the-counter drugs (Davis et al. 2011). In order to complete the description of the HPD user and his/her work environment, two measurements are also commonly performed: audiometry tests and global noise level measurement at the workplace (in $\mathrm{dB}(\mathrm{A})$ ). Even if many modifying factors can be identified from the literature, each comfort study measures few of them. However, the data stemmed from these questionnaires are useful to conduct statistical analyses and identify which modifying factors may significantly impact the perceived comfort.

The second group of questionnaires is distributed during or after the wearing of the tested HPD to evaluate the attributes of perceived comfort and/or the HPD design factors that might influence the perceived comfort. These questionnaires usually measure the HPD wearer's opinions/feelings through rating scales such as unipolar Likert-type scales (Brown-Rothwell 1986; Du, Homma, and Saunders 2008; Hsu et al. 2004), bipolar scales (Behar and Desormeaux 1986; Casali et al. 1987; Epps and Casali 1985; Park and Casali 1991) or both (Sweetland 1983; Gonçalves et al. 2015). Even if it is based on a restricted 
construct of comfort, a questionnaire developed by Park and Casali $(1991 ; 1992)$ generates consensus and is used as is or slightly modified in many studies (Arezes and Miguel 2001; Arezes and Miguel 2002; Byrne et al. 2011; Davis et al. 2011; Davis and Shaw 2016; Samelli et al. 2018; Sviech et al. 2013). This questionnaire, developed for both earplugs and earmuffs, uses 13 bipolar adjectival scales for assessing both attributes of the physical and functional comfort dimensions (e.g., "no uncomfortable pressure/uncomfortable pressure”, "tight/loose”) and design factors of the HPDs affecting these comfort attributes (e.g., “soft/hard”, “smooth/rough”). It also includes a scale "uncomfortable/comfortable” used to measure the participants' global perception of HPD comfort and identify the HPD attributes associated with comfort (see next sub-section). This scale is thus referred to as the "central scale” in (Arezes and Miguel 2002). It is worth noting that this questionnaire is the combination of two previous questionnaires designed specifically for earplugs (Epps and Casali 1985) and earmuffs (Casali et al. 1987). The derived questionnaire thus contains descriptors that were previously proposed for earmuffs only (and thus potentially not adapted to earplugs) and does not contain some indicators originally developed for the earplug questionnaire (e.g. "shallow/deep”, “expanded/contracted”). Regarding the rating scales, there is no consensus in the literature on the preferred scales (unipolar or bipolar) to be adopted according to the HPD aspect to be measured. Regarding the length of the questionnaire, the literature shows that short questionnaires (from 5 to 14 questions) are usually preferred; which could be due to practical reasons (especially for field studies). However, Brown-Rothwell (1986) mention that longer questionnaire increases its reliability by canceling out random errors on particular items.

The third group of questionnaires is offered to participants at the end of the test campaign (i.e., once all the HPDs selected for the study have been tested) and is intended to reflect their overall experience. They are mainly used to rank the tested HPDs, the HPD characteristics or the comfort attributes in order of preference (Arezes, Abelenda, and Braga 2008; Brown-Rothwell 1986; Casali et al. 1987; Du, Homma, and Saunders 2008; Epps and Casali 1985; Ivergard and Nicholl 1976; Park and Casali 1991). This group of questionnaires is not used or little used in studies on the assessment of the comfort of HPDs, which are generally limited to the first two groups. 


\section{Determination of the main attributes}

In all aforementioned studies based on rating scales, the responses obtained on each of the psychometric scales (e.g., bipolar, Likert) are then converted into numerical scores. In this paper, the score corresponding to the measured attribute is called a Specific Comfort Level (SCL) and the result of a main scale (e.g., the "comfortable/uncomfortable” central bipolar scale in (Casali et al. 1987; Epps and Casali 1985; Park and Casali 1991)) is called the Overall Comfort Level (OCL).

Two methods are mainly used in the literature to identify, for a given HPD, whether an attribute is significantly associated with perceived overall comfort: (1) calculating the percentage of participants who identified this attribute as a source of discomfort (Arezes, Abelenda, and Braga 2008; Brown-Rothwell 1986; Hsu et al. 2004) or (2) by statistically analyzing the degree of correlation between the SCL (= average score given to the measured attribute by all participants) of each attribute and the OCL (= average score given to the main “comfortable/uncomfortable” scale by all participants) (Casali et al. 1987; Epps and Casali 1985; Park and Casali 1991). Other works also identify the attributes showing significant variations between the different tested HPDs through statistical analyses (Arezes, Abelenda, and Braga 2008; Brown-Rothwell 1986).

\section{Quantification of the global subjective perception: a global index}

Multiple authors propose to compute a numerical value to quantify the overall subjective perception relative to the use of a given HPD. This value or index is generally computed from the combination of several SCLs. To the best of our knowledge, Sweetland (1983) is the first to carry out this exercise of summing the SCL to give an overall preferred rank order of wearability. For each of the nine tested HPDs, Sweetland calculates a SCL for each of the six proposed dimensions (i.e., "attenuation”, "interference”, "pressure”, “convenience”, “acceptance” and “comfort”) and then a global wearability score by adding only four of the intermediate categories (i.e., "pressure”, “convenience”, “acceptance” and “comfort”). Sweetland uses both types of levels (intermediate and global) to classify and analyze HPD performance. Later Brown-Rothwell (1986) also proposes a global index, called index of acceptance, computed as the mean value of two other indices: a convenience 
index calculated as the mean score obtained for three attributes (i.e., "insertion”, "stability” and “intrusion”) and a comfort index calculated as the mean score obtained for five attributes (i.e., “sensation”, “satisfaction”, “tolerance”, “voice level” and “appeal”). Behar and Desormeaux (1986) and Behar and Jackson (1987) also propose a global comfort score calculated as a weighted sum of the score obtained for the different items of their questionnaire. Other authors suggest a Comfort Index referred to as CI (Casali et al. 1987; Epps and Casali 1985; Park and Casali 1991) and calculated as the unweighted sum of the OCL and of the SCL which are significantly correlated to the OCL (see previous subsection). Not using attributes weakly correlated to the OCL in the calculation of the CI is justified by the fact that these attributes can be considered in practice as not significant (Park and Casali 1991). The CI proposed by Epps and Casali (1985) appears to reach consensus and is subsequently used as is or slightly modified in (Arezes and Miguel 2002; Byrne et al. 2011; Davis et al. 2011; Murphy et al. 2007; Sviech et al. 2013). Note that, this CI only accounts for attributes of the physical and functional dimensions of comfort and its constitutive comfort attributes vary across studies.

\section{Main comfort attributes of earplugs}

This section is dedicated to earplug-type HPDs. The different earplug families are first presented. Then, the results of studies evaluating comfort through SCL and OCL and thus making it possible to identify the main comfort attributes are presented for each of the proposed 4 comfort dimensions. Global comfort indices (such as CI) are not discussed in the following since their construction varies across studies which hinders comparative analysis.

\section{Earplugs}

Earplugs are the most commonly used HPDs in the workplace (source: 3M Europe; numbers in North America are not available). However, the level of protection provided by earplugs is known to be less reliable than the one provided by earmuff because of the greater difficulty in properly positioning this type of HPD. Earplugs are therefore generally recommended for use over long periods of time unlike earmuffs that can more easily be 
removed and reinstalled without damaging their attenuation performance by improper repositioning.

There is a large variety of earplugs available in the marketplace that differ in shape, material, texture and design. Until now, earplugs have been characterized only by the sound attenuation they provide through an objective indicator referred to as Noise Reduction Rating (NRR). NRR is measured in a laboratory environment in conformance with the standard ANSI S12.6 (American National Standard 2016). Because perceived comfort also depends on earplug characteristics, the following paragraph briefly recalls the six main earplug families as defined by Berger and Voix (2018). “Roll-down foam” earplugs are made of compressible foam. They are generally cylindrical (or bullet shaped) and of a diameter greater than the diameter of the "medium” auditory canal of human beings (often given between $7 \mathrm{~mm}$ and $9 \mathrm{~mm}$ in the literature). The earplug is compressed between the fingers and then inserted into the earcanal (Berger 2001). It then tends to progressively recover its initial shape thus providing the acoustic sealing when making contact with the earcanal skin. It is worth noting that roll-down foam earplugs can be found in various shapes and sizes (diameter or length). Standard CSA Z94.2 (Canadian Standards Association 2014) stresses the importance in selecting adequate earplug size taking into account (physical) comfort aspects. "Premolded” earplugs are made of a semi-rigid rod, facilitating insertion, which is covered with one or several flexible flanges. The latter create the acoustic sealing when deformed by the earcanal walls. "Push-to-fit foam" earplugs are also made of a semi-rigid rod but this time covered with a dome of foam similar to that used in roll-down foam earplugs. "Semi-insert" earplugs are made of soft tips (generally of conical shape) attached to a headband. "Custom molded” earplugs are usually made from earcanal impressions. Softness and sound attenuation of these earplugs can be controlled respectively by the choice of material (e.g., soft silicone or acrylic) and acoustic filter selected according to the noise level of the work environment. Finally, "Formable" earplugs are made from malleable materials such as silicone putty or wax covered by cotton. The latter is not frequently used on the field and thus rarely investigated in the HPD comfort literature. 


\section{Physical dimension of comfort}

With respect to the physical comfort dimension, the main attributes emerging from comfort studies are: "pain", "static mechanical pressure" and "irritation" (attribute related to earplug texture) (Arezes, Abelenda, and Braga 2008; Bockstael et al. 2012; BrownRothwell 1986; Casali et al. 1987; Epps and Casali 1985; Gonçalves et al. 2015; Hsu et al. 2004; Laitinen and Poulsen 2008; Park and Casali 1991; Sviech et al. 2013). Gerges and Casali (2007) mention that the mechanical pressure exerted by the HPD (earplugs and earmuffs) on the skin and the soft tissues and bones it covers is probably the most direct cause of discomfort. This source of discomfort is mentioned in a large number of publications (ex. (Casali et al. 1987; Santoni and Fiorini 2010; Wheeler and Glorig 1956; Zwislocki 1958)). The static mechanical pressure (SMP) is a characteristic of the tribological system "earcanal/earplug" and is therefore related to the properties of both components (e.g., geometry, stiffness). Excessive SMP exerted on the earcanal walls causes ischemia of the skin and results in pain (Wheeler and Glorig 1956). The studies by Casali et al. (1987) and Park and Casali (1991) show that the generic attribute "pain" is strongly correlated with their construct of overall comfort. An important aspect of the mechanical discomfort associated to the SMP is also related with the movement of the lower jaw (due to speaking, eating, swallowing, yawning, chewing...) (Darkner, Larsen, and Paulsen 2007; Wheeler and Glorig 1956). Indeed, jaw movement leads to a significant deformation of the tragus and earcanal (Darkner, Larsen, and Paulsen 2007). Flexible earplugs can thus be favored compared to more rigid ones (such as customs) in order to limit discomfort related to SMP (Brown-Rothwell 1986; Wheeler and Glorig 1956); especially for users having to talk during their work.

Finally, irritation of the earcanal is mentioned in (Anon. 1982; Arezes, Abelenda, and Braga 2008; Bhattacharya, Tripathi, and Kashyap 1993; Casali et al. 1987; Davis 2008; Hsu et al. 2004; Ivarsson, Toremalm, and Brühl 1990; Sweetland 1983) and pain during withdrawal in (Casali et al. 1987). Brown-Rothwell (1986) (citing (Chow, Juvinall, and Cockrell 1976)) mention that friction between the skin and the earplug material is due to an "interface shear" resulting from an angled distortion of the skin tissue tending to collapse the fine blood capillaries. Irritation can logically be related to the texture of the earplugs 
(Arezes, Abelenda, and Braga 2008). It is also related to other earplug design factors associated with thermal comfort (included in the physical dimension of comfort in this paper) such as "ability for heat dispersing" and "ability for perspiration absorption". Indeed, irritation may occur if the HPD does not have the ability to absorb humidity (Arezes, Abelenda, and Braga 2008). It is worth mentioning that Arezes, Abelenda and Braga (2008) also found that the last two HPD factors are considered of great importance for participants working in hot environments.

The mechanical discomforts (associated to SMP or friction) perceived by an individual can be partly due to the difference in shape or in diameter between his/her earcanal and the earplug. Both differences are particularly true for one-size-fits-all earplugs having universal sizes (such as premolded and push-to-fit-foam earplugs and some roll-down foam earplugs), the shape and diameter of which must adapt to those of the earcanal. Wheeler and Glorig (1956) assume that the (physical) discomfort is more likely to be due to the pressure exerted on the first bend in the canal by the distal end of the protector. This has been confirmed in (Tufts, Chen, and Marshall 2013) for some wearers of custom molded earplugs who found them comfortable when the portion that lay beyond the second bend was removed. To elaborate further this point, Wheeler and Glorig mention that the first third of the earcanal (mostly constituted of soft tissues and cartilage) is rather flexible due to its structure and that the deformation of the elliptical cross-section of the earcanal in order to comply with the earplug shape will not generate mechanical discomfort. On the contrary, Yu et al. (2015) while observing a 40\% difference between height and width of earcanal opening advise to replace cylindrical earplugs by earplugs with elliptical crosssection shape. This statement seems to be confirmed by Brown-Rothwell (1986) observations following average answers to its descriptive question where the participant is invited to indicate on a schematic of the ear (pinna, canal entrance and earcanal) the locations of greatest perceived physical discomfort. Indeed, it is shown that the earcanal entrance is the least comfortable region for all tested earplugs. It is worth noting that these conclusions are either qualitative based on researcher assumptions (Wheeler and Glorig 1956; Yu et al. 2015), or quantitative but based on participant perception (Brown-Rothwell 1986). Quantitative analyses that are more rigorous would require images of open and 
occluded earcanals in order to have a more precise knowledge of the earplug position within the earcanal and objective quantification of the earcanal deformation. This type of analysis are currently under investigation by Benacchio et al. (2016; 2017; 2018) using medical imaging strategies.

\section{Functional dimension of comfort}

With respect to the functional dimension of comfort, the main attributes emerging from comfort studies are: "insertion”, "annoyance”, "unhandy”, "stability" (maintaining in position) and "intrusion" (inhibit head movement) (Arezes, Abelenda, and Braga 2008; Bockstael et al. 2012; Brown-Rothwell 1986; Coles and Rice 1966; Davis 2008; Gonçalves et al. 2015; Hsu et al. 2004; Park and Casali 1991; Samelli et al. 2018; Sweetland 1983; Laitinen and Poulsen 2008). The hygienic aspect is sometimes mentioned (Acton 1977; Davillerd 2001; Sweetland 1983), the roll-down foam earplugs being particularly easily contaminated and perceived as such.

In a study by Coles and Rice (1966), the earplug considered to be the least comfortable is described as the least easy to insert and having a tendency to fall (but allowing better intelligibility, which highlights the trade-offs that may exist when evaluating comfort). Concerning the maintaining in position, Sweetland (1983) insisted that it can be an important factor in the estimation of comfort (confirming conclusion of ref. (Coles and Rice 1966)), especially in difficult working conditions (e.g., physical, hot environment). As for the convenience of installation, the maintaining in position will be linked as much to the geometry as to the chosen material or to the working conditions (e.g., humidity and heat). It is interesting to note that in Park and Casali study (Park and Casali 1991), the bothersome and cumbersome attributes are significantly correlated with the concept of discomfort, which means a priori that, for the participants involved in this study, the functional dimension of comfort is an integral part of their concept of comfort.

However, other studies tend to relativize the importance of some functional attributes on perceived comfort (Arezes, Abelenda, and Braga 2008; Arezes and Miguel 2002; BrownRothwell 1986; Sviech et al. 2013). For example, “difficulty to perform tasks” (Arezes, Abelenda, and Braga 2008) and "convenience” (Brown-Rothwell 1986) are found to be the 
attributes the least correlated to perceived comfort. Two scale descriptors of the functional dimension of comfort "complicated/simple” and "easy to put/difficult to put” added to the questionnaire of Park and Casali by Arezes and Miguel (2002) and Sviech et al. (2013) are not significantly correlated with global comfort (assessed via OCL). Also, and contrary to the observations of Coles and Rice mentioned above, Casali et al. (1987) show that "ease of insertion" and perceived comfort do not always go hand in hand. This last observation could stem from the fact that Casali et al. (1987) (also in (Epps and Casali 1985)) differentiate the constructs of comfort and general preference indirectly indicating to the participant that comfort can be reduced to its physical dimension (rather associated with pain), thus excluding functional factors. This puts into perspective the importance of the questionnaire writing and the ability to convey the researchers' own construct of comfort through the chosen questions and the correlations between them.

\section{Acoustical dimension of comfort}

Unlike the two aforementioned comfort dimensions, the acoustical dimension can be more complex to analyse since HPD can provide not only acoustical discomfort but also comfort (considering a priori that only discomforts can be provided by HPD for both the physical and functional comfort dimensions). Indeed, HPD is known to reduce noise annoyance (Melamed et al. 1996; Melamed, Rabinowitz, and Green 1994) and to slightly improve ability of normal hearing individuals to hear useful signals (e.g., speech, danger signals) in high-noise level environments (Berger and Voix 2018; Berger 1990; Giguère et al. 2010). On the contrary, HPDs can deteriorate communication (hearing and speech) and increase difficulty in hearing useful machinery noise and warning signals (known as significant factors preventing HPD use and correct use) for some individuals and especially those with hearing loss (Berger 1990; Berger 2003; Giguère et al. 2010). These aspects are generally associated with overprotection (Canadian Standards Association 2014) (see sec. 9.8) and to avoid it, the Canadian standard recommends not to decrease in-ear sound pressure levels below $70 \mathrm{~dB}(\mathrm{~A})$. Despite their importance, the aforementioned attributes of the acoustical comfort dimension are generally not accounted for in the studies dedicated to HPD comfort, the later being usually defined only by its physical and functional dimensions. There is consensus in the literature that physical comfort and sound attenuation associated with the 
protector should be investigated concurrently (Byrne et al. 2011; Davis and Shaw 2016; Samelli et al. 2018). Indeed, to be effective, an earplug must exert sufficient pressure against the circumference of the earcanal wall to form a tight seal. The anatomy of the outer ear can thus impact the quality of the acoustic seal. For example, Wheeler and Glorig (1956) assume that users with a tragus extending too far backwards over the canal opening may exert a pressure on the earplug, forcing it backward and outward and displacing it enough to produce an acoustic leak.

Multiple studies on HPD comfort accounting for attributes of the acoustical dimension show that this dimension affects significantly the overall comfort (Bockstael et al. 2012; Brown-Rothwell 1986; Gonçalves et al. 2015; Hsu et al. 2004). For example, Hsu et al. (2004) show that the attribute "having difficulties in conversations" is the one pointed out by workers as the main reason of perceived discomfort (just before the attribute "sense of oppression” belonging in their work to the physical dimension of comfort but which could also be included in the psychological dimension proposed in this paper). Gonçalves et al. (2015) show that "HPD noise attenuation" and "oral communication possibility" are the most important aspects considered by the participants. However, other studies tend to relativize the importance of some acoustical attributes on perceived comfort (Arezes, Abelenda, and Braga 2008; Davis 2008; Ivarsson, Toremalm, and Brühl 1990). For example, Davis (2008) mentions that experienced HPD users preferred to be overprotected (i.e., hearing protection which reduced the noise exposure level to $<70 \mathrm{dBA}$ ) in spite of sacrificing verbal communication. Ivarsson Toremalm and Brühl (1990) find only a minor impact of the intelligibility on reported comfort. Arezes Abelenda and Braga (2008) find that "attenuation" and "intelligibility" are only placed $6^{\text {th }}$ in the ranking of importance of comfort attributes. The correlation between HPD attenuation (quantified by the personal attenuation rating) and HPD preference is not direct however and multiple studies lead to different observations: no correlation is found in (Samelli et al. 2018) and HPD preference decreases with HPD attenuation in (Byrne et al. 2011).

Finally, although the "occlusion effect" attribute is deemed to be a significant discomfort attribute for earplugs wearers such as workers (Berger and Voix 2018; Casali et al. 1987), 
musicians (Bernier 2013; Killion 2012; Laitinen and Poulsen 2008) or hearing aids wearers (Branda 2012; Conrad and Rout 2013; French-Saint George and Barr-Hamilton 1978; Furstenberg, Gordon, and Baccaro 1988; Killion, Wilber, and Gudmundsen 1988; Kochkin 2000; Mackenzie, Browning, and McClymont 1989), few HPD comfort studies incorporate questions about this effect in their questionnaires and it is therefore very difficult to estimate its contribution to overall comfort in general. Brown-Rothwell (1986) measures an item on the voice level (item: "I find it difficult to judge how loudly to speak to others") and relates it to the degree of occlusion experienced and thus to the possible occlusion effect. The perceived occlusion effect (Hsu et al. 2004; Laitinen and Poulsen 2008; Samelli et al. 2018; Santoni and Fiorini 2010) is an attribute difficult to isolate because it could be revealed through various attributes measured in comfort questionnaires such as "feeling of oppression” (which can also be related to the psychological dimension), "blocked ear” or even "sound attenuation". In parallel, the question of the correct understanding of the term “occlusion” can also be raised and emphasizes again the importance of a well-written questionnaire but also in accordance with the profile of the participants. It is worth noting that the vast majority of studies on the relationship between comfort and perceived occlusion deal with hearing aids (Alworth et al. 2010). The perceived occlusion is evaluated from perception tests of the quality of one's own voice (by reading sentences displayed on a screen aloud while wearing the hearing aid) or listening tests of external voices (Conrad and Rout 2013). Examples of attributes used to judge the quality of the voice are "boomy”, “hollow”, “resonant”, “sounds like talking in a barrel”.

\section{Psychological dimension of comfort}

As mentioned previously, attributes of the psychological dimension of comfort can rarely be found in the literature related to HPD comfort. Based on Ergonomics and Psychology literature, Terroir, Doutres and Sgard (2017) report several attributes belonging to this

comfort dimension: e.g., habituation, protection feeling, isolation feeling. Therefore, "Feeling of isolation" is an attribute of the reference questionnaire of Park and Casali (1991) that could be associated to this dimension. However, comfort studies based on Casali et al.' questionnaires show that it is never significantly correlated with the global dimension of comfort OCL (Arezes and Miguel 2002; Casali 1992; Davis and Shaw 2016; 
Park and Casali 1991; Sviech et al. 2013) and thus never used in the CI calculation. As mentioned previously, Brown-Rothwell (1986) proposes a comfort dimension composed of 3 different sub-dimensions: the "sensation" sub-dimension composed of physical attributes (i.e., "pushing my ears”, "make my ears sore” and "make my ear ache”), the "satisfaction" sub-dimension composed of psychological attributes (i.e., "very comfortable" which is in fact extremely general, "find pleasant" and "find relaxing”) and the "tolerance" sub-dimension composed of compound attributes (i.e., "happy to wear" and “got used to”). Brown-Rothwell does not rank these attributes by order of importance but shows that the comfort dimension he proposes and its sub-dimensions allow differentiating significantly the tested earplugs. Thus, he demonstrates a subtle, yet important, difference between the psychological "sensation" of comfort and the perceived "satisfaction" and particularly for the custom earplug which has a high rating for the comfort "sensation" but a low rating on the satisfaction sub-dimension.

\section{Conclusion}

The word comfort, in the framework of HPD use, is generally employed for designating subjective perceptions related to the mechanical contact between the HPD and the body. Even if this concept is shared by users, it seems simplistic and ambiguous since other aspects (e.g., acoustical, functional and psychological) play their role in the global perception of comfort (as well as modifying factors) and affect the correct and consistent use of HPDs. In the light of the observations obtained from this literature review, this paper proposed a multidimensional construct of HPD comfort based on four dimensions. Seen through the prism of this holistic construct, the main comfort attributes of earplugs have been identified for the following comfort dimensions:

- Physical: “pain”, “static mechanical pressure” and “irritation”.

- Functional: “insertion”, “annoyance”, “unhandy”, “stability” (maintaining in position) and “intrusion” (inhibit head movement).

- Acoustical: "having difficulties in conversations” (hearing and speech) and "having difficulties in hearing useful sounds” (machinery noise and warning signals). 
- Psychological: "acceptability", "pleasant", "relaxing", "happy to wear", "got used" to". Unfortunately, attributes of this comfort dimension can rarely be found in the literature related to HPD comfort. Only a few studies mention their importance and even show these attributes can allow for differentiating significantly different earplugs models.

This literature review shows that quantifiable differences are observed in the perceived comfort provided by earplugs. However, due to the subjective nature of comfort, a wide variety of comfort constructs and measurement methods can be found. It is then difficult (i) to compare the results of the assessment of the comfort available in the literature and (ii) rank the comfort attributes in any order of importance. A future literature review will be oriented towards the analysis of the main factors affecting HPD comfort assessment (e.g, construct of comfort, characteristics of the measurement environment and of the participants). A better understanding of these factors is necessary in order to improve measurement methods, data analysis and ultimately, for designing more comfortable HPDs adapted to the wearer and his/her work environment.

\section{Acknowledgements}

The authors acknowledge IRSST (Montréal, Québec, Canada) and INRS (Vandoeuvre-lèsNancy, France) for funding this research. The authors would also like to thank Marie Stewart from ÉTS library (Montréal, Québec, Canada) for finding/digging old and "hard to find" references.

\section{Funding}

This study was financially supported by IRSST, INRS and MITACS. 


\section{References}

Abel, S.M. 2008. "Barriers to Hearing Conservation Programs in Combat Arms Occupations.” Aviation, Space, and Environmental Medicine 79 (6): 591-598. doi:10.3357/ASEM.2262.2008.

Abel, S.M., H. Kunov, M.K. Pichora-Fuller, and P.W. Alberti. 1985. “Signal Detection in Industrial Noise: Effects of Noise Exposure History, Hearing Loss, and the Use of Ear Protection.” Scandinavian Audiology $14 \quad$ (3): 161-173. doi:10.3109/01050398509045937.

Acton, W. L. 1977. "Problems Associated with the Use of Hearing Protection.” The Annals of Occupational Hygiene 20 (4): 387-395. doi:10.1093/annhyg/20.4.387.

Alworth, L. N., P. N. Plyler, M. B. Reber, and P. M. Johnstone. 2010. "The Effects of Receiver Placement on Probe Microphone, Performance, and Subjective Measures with Open Canal Hearing Instruments." Journal of the American Academy of Audiology 21 (4): 249-266. doi:10.3766/jaaa.21.4.4.

American National Standard. 2016. Methods Measuring Real-Ear Attenuation of Hearing Protectors. ANSI/ASA S12.6. American National Standard.

Anon. 1982. "Hearing Protection - Progress Continues (in Swedish).” Forelagshalsovard No. 3: 9-12.

Arezes, P. M., C. Abelenda, and A. C. Braga. 2008. “An Evaluation of Comfort Afforded by Hearing Protection Devices.” In Proceedings of the AHFE 2008, 1-8.

Arezes, P. M., and A. S. Miguel. 2001. "Efficiency vs. Acceptability of Hearing Protectors in Industrial Environments." In Rivista Italiana Di Acustica, 25:165-166. http://repositorium.sdum.uminho.pt/handle/1822/24452.

Arezes, P. M., and A. S. Miguel. 2002. "Hearing Protectors Acceptability in Noisy Environments." The Annals of Occupational Hygiene 46 (6): 531-536. doi:10.1093/annhyg/mef067.

Arezes, P. M., and A. S. Miguel. 2005a. "Individual Perception of Noise Exposure and Hearing Protection in Industry.” Human Factors 47 (4): 683-692.

Arezes, P. M., and A. S. Miguel. 2005b. "Hearing Protection Use in Industry: The Role of Risk Perception.” Safety Science 43 (4): 253-267. doi:10.1016/j.ssci.2005.07.002.

Arezes, P. M., and A. S. Miguel. 2006. "Does Risk Recognition Affect Workers' Hearing Protection Utilisation Rate?” International Journal of Industrial Ergonomics 36 (12): 1037-1043. doi:10.1016/j.ergon.2006.09.005.

Baker, A.T., S. Lee, and F. Mayfield. 2010. "Evaluating Hearing Protection Comfort through Computer Modeling.” In Proceedings of SIMULIA Customer Conference, 15.

Behar, A., and J. Desormeaux. 1986. “Testing of Hearing Protectors at Ontario Hydro.” Sound Vib. 20 (October): 16-18.

Behar, A., and R. A. Jackson. 1987. "Selection of Hearing Protectors.” Applied Acoustics 22 (1): 34-35. doi:10.1016/0003-682X(87)90013-2.

Behar, A., R. Segu, and F. Russo. 2014. "Comfort from Hearing Protectors.” Canadian Acoustics 42 (3).

Benacchio, S., O. Doutres, A. Le Troter, A. Varoquaux, E. Wagnac, V. Callot, and F. Sgard. 2018. "Estimation of the Ear Canal Displacement Field Due to In-Ear Device 
Insertion Using a Registration Method on a Human-like Artificial Ear.” Hearing Research 365 (August): 16-27. doi:10.1016/j.heares.2018.05.019.

Benacchio, S., A. Varoquaux, A. Le Troter, E. Wagnac, O. Doutres, D. Bendahan, V. Callot, and F. Sgard. 2017. "MRI Investigation of the Ear Canal Deformation Due to Earplugs: A First Step toward Understanding Wearing Comfort.” The Journal of the Acoustical Society of America 141 (5): 4024-4024. doi:10.1121/1.4989266.

Benacchio, S., A. Varoquaux, E. Wagnac, O. Doutres, V. Callot, D. Bendahan, and F. Sgard. 2016. "Ear Canal Deformations by Various Earplugs: An in Situ Investigation Using MRI.” Canadian Acoustics 44 (3).

Berger, E. H. 2001. “Tips and Tools for Fitting and Using E.A.R Foam Earplugs.” E.A.R.CAL SM Laboratory, Indianapolis.

Berger, E. H. 2003. “Hearing Protection Devices.” In The Noise Manual, edited by E. H. Berger and M. Layne, Revised Fifth Edition, 379-454. Fairfax, VA, USA: AHIA Press.

Berger, E.H. 1990. "Hearing Protection-The State of the Art (circa 1990) and Research Priorities for the Coming Decade.” In Program and Abstracts of the NIH Consensus Development Conference on Noise and Hearing Loss, 91-96. Bethesda, MD: National Inst. of Health.

Berger, E.H., and J. Voix. 2018. "Hearing Protection Devices.” In The Noise Manual, 6th Edition (in Press), American Industrial Hygiene Association. AIHA Press.

Berger, E.H., J. Voix, R.W. Kieper, and C. Le Cocq. 2011. "Development and Validation of a Field Microphone-in-Real-Ear Approach for Measuring Hearing Protector Attenuation.” Noise and Health 13 (51): 163-175. doi:10.4103/1463-1741.77214.

Bernier, A. 2013. "Towards an Active Hearing Protection Device for Musicians, Master's Thesis, École de Technologie Supérieure, Montréal, Canada.” M.A.Sc thesis, Canada: Ecole de Technologie Superieure (Canada).

Bhattacharya, S. K., S. R. Tripathi, and S.K. Kashyap. 1993. “Assessment of Comfort of Various Hearing Protection Devices (HPD).” Journal of Human Ergology 22: 163172.

Bockstael, A., D. Botteldooren, L. De Bruyne, and B. Vinck. 2012. "Personal Hearing Protection and Comfort: Indispensable but Not a Matter of Course.” In Proceedings of the European Conference on Noise Control - Euronoise. Prague, Czech Republic.

Bockstael, A., L. De Bruyne, and B. B. Vinck. 2011. "Attitudes and Beliefs Concerning Hearing Protectors and Noise Exposure.” Canadian Acoustics 39 (3): 92-93.

Bockstael, A., H. Keppler, and D. Botteldooren. 2015. "Musician Earplugs: Appreciation and Protection." Noise and Health 17 (77): 198-208. doi:10.4103/14631741.160688.

Branda, E. 2012. "Deep Canal Fittings: Advantages, Challenges, and a New Approach.” Hearing Review 19 (4): 24-27.

Branson, D.H., and M.M. Sweeney. 1991. "Conceptualization and Measurement of Clothing Comfort: Toward a Metatheory.” In Critical Linkages in Textiles and Clothing: Theory, Method and Practice, International Textiles and Apparel Association ITAA Special Publication, 94-105. Monument, CO, USA: S. Kaiser and M.L. Damhorst (Eds.). 
Broughton, KA. 1995. Comfort Aspects of Ear Protection, A Review. 40,029. UK: Health and Safety Executive.

Brown, A.D., B.T. Beemer, N.T. Greene, T. Argo, G.D. Meegan, and D.J. Tollin. 2015. "Effects of Active and Passive Hearing Protection Devices on Sound Source Localization, Speech Recognition, and Tone Detection.” Edited by J. Snyder. PLoS ONE 10 (8): e0136568. doi:10.1371/journal.pone.0136568.

Brown-Rothwell, D.J. 1986. "The Comfort of Earplugs-Basis for a Descriptive Model, Unpublished Master's Thesis, University of Southampton, United Kingdom.” Master's thesis, England: University of Southampton.

Byrne, D. C., R. R. Davis, P. B. Shaw, B. M. Specht, and A. N. Holland. 2011. "Relationship between Comfort and Attenuation Measurements for Two Types of Earplugs.” Noise and Health 13 (51): 86-92. doi:10.4103/1463-1741.77193.

Canadian Centre for Occupational Health and Safety. 2017. "OSH Answers Fact Sheets, Hearing Protectors.” Canadian Centre for Occupational Health and Safety. https://www.ccohs.ca/oshanswers/prevention/ppe/ear_prot.html.

Canadian Standards Association. 2014. Hearing Protection Devices - Performance, Selection, Care, and Use. CSA Z94.2-14.

Canetto, P. 2009. “Hearing Protectors: Topicality and Research Needs.” International Journal of Occupational Safety and Ergonomics 15 (2): 141-153.

Casali, J. G. 1992. "Comfort: The 'Other' Criterion for Hearing Protector Design and Selection." In Proceedings of the Hearing Conservation Conference, 47-53. University of Kentucky, Lexington, Kentucky, USA. https://www.cdc.gov/niosh/nioshtic-2/00213191.html.

Casali, J. G., and S. T. Lam. 1986. "Over-the-Ear Industrial Hearing Protectors: An Assessment of Comfort Issues." In Proceedings of the Human Factors Society Annual Meeting, 30:1428-1432. SAGE Publications Sage CA: Los Angeles, CA.

Casali, J. G., and M. -Y. Park. 1990. "Attenuation Performance of Four Hearing Protectors under Dynamic Movement and Different User Fitting Conditions.” Human Factors 32 (1): 9-25.

Casali, J. G., V. Tech, S. T. Lam, and B. W. Epps. 1987. "Rating and Ranking Methods for Hearing Protector Wearability.” Sound \& Vibration 21 (12): 10-18.

Chow, W.W., R.C. Juvinall, and J.L. Cockrell. 1976. "Effects and Characteristics of Cushion Covering Membranes.” In Bed Sore Biomechanics, 95-102. Strathclyde Bioengineering Seminars. Palgrave, London. doi:10.1007/978-1-349-02492-6_13.

Coles, R. R. A., and C. G. Rice. 1966. "Speech Communications Effects and Temporary Threshold Shift Reduction Provided by V51R and Selectone-K Earplugs under Conditions of High Intensity Impulsive Noise.” Journal of Sound Vibration 4 (2): 156-171. doi:10.1016/0022-460X(66)90119-2.

Conrad, S., and A. Rout. 2013. "Perceived Occlusion and Comfort in Receiver-in-the-Ear Hearing Aids.” American Journal of Audiology 22 (2): 283-290. doi:10.1044/10590889(2013/11-0025).

Costa, S., and P. M. Arezes. 2013. "On the Nature of Hearing Protection Devices Usage Prediction.” In Occupational Safety and Hygiene, 453-456. doi:10.1201/b1439193. 
Cramer, M.E., M. J. Wendl, H. Sayles, E. Duysen, and C. Achutan. 2017. "Knowledge, Attitudes, and Practices for Respiratory and Hearing Health among Midwestern Farmers.” Public Health Nursing 34 (4): 348-358. doi:10.1111/phn.12306.

Damongeot, A. 1977. The efficiency and comfort of personal protectors for the control of noise (in french). 301/RI. Vandoeuvre, France: Natl. Inst. Res. Safety.

Damongeot, A., M. Tiserand, G. Krawsky, P. Grosdemange, and D. Lievin. 1982. "Evaluation of the Comfort of Personal Hearing Protection.” In Personal Hearing Protection in Industry, 151-162. New-York: Alberti PW, Raven Press.

Darkner, S., R. Larsen, and R.R. Paulsen. 2007. "Analysis of Deformation of the Human Ear and Canal Caused by Mandibular Movement." In Proceedings of the International Conference on Medical Image Computing and Computer-Assisted Intervention, 801-808. Springer.

Davillerd, C. 2001. Prévention et Port Des Équipements de Protection Individuelle. 5. Une Usine Métallurgique (in Fench). Research Report Notes scientifiques et techniques de l'INRS NS 214 (in French). Institut National de Recherche et de Sécurité (INRS).

Davis, R. R. 2008. "What Do We Know about Hearing Protector Comfort?” Noise and Health 10 (40): 83-89.

Davis, R. R., W. J. Murphy, D. C. Byrne, and P. B. Shaw. 2011. “Acceptance of a SemiCustom Hearing Protector by Manufacturing Workers.” Journal of Occupational and Environmental Hygiene 8 (12): doi:10.1080/15459624.2011.626262.

Davis, R. R., and P. B. Shaw. 2016. "Hearing Protector Comfort and Personal Attenuation Ratings: A Real World Study." In Proceedings of the National Hearing Conservation Association. San Diego, CA, USA.

Davis, R. R., and W. Karl Sieber. 2002. "Hearing Protector Use in Noise-Exposed Workers: A Retrospective Look at 1983.” AIHA Journal 63 (2): 199-204. doi:10.1080/15428110208984705.

De Looze, Michiel P., Lottie F. M. Kuijt-Evers, and Jaap Van DieëN. 2003. "Sitting Comfort and Discomfort and the Relationships with Objective Measures." Ergonomics 46 (10): 985-997. doi:10.1080/0014013031000121977.

Du, Y., K. Homma, and W.R. Saunders. 2008. "Noise Attenuation Performance of DeepInsert Custom Earplugs under Single and Double Hearing Protection.” Noise Control Engineering Journal 56 (3): 183-202.

Edelson, J., R. Neitzel, H. Meischke, W.E. Daniell, L. Sheppard, B. Stover, and N. Seixas. 2009. "Predictors of Hearing Protection Use in Construction Workers." The Annals of Occupational Hygiene 53 (6): 605-615. doi:10.1093/annhyg/mep039.

Epps, B. W., and J. G. Casali. 1985. "Hearing Protection Device Comfort and User Preference: An Investigation and Evaluation Methodology.” In Proceedings of the Human Factors Society - 29th Annual Meeting, 29:814-818.

Flugrath, J.M., and J.B. Tuberville. 1972. “The Effectiveness of Earplugs.” Sound and Vibration 6 (5): 32-33.

French-Saint George, M., and R. M. Barr-Hamilton. 1978. "Relief of the Occluded Ear Sensation to Improve Earmold Comfort." Journal of the American Audiology Society 4 (1): 30-35. 
Furstenberg, J.F., D.G. Gordon, and P.M. Baccaro. 1988. “A Conglomerate Approach to Hearing Aid Evaluation and Fitting.” SEMINARS IN HEARING 9 (3): 217-223.

Gerges, S.N.Y. 2012. "Earmuff Comfort." Applied Acoustics 73 (10): 1003-1012. doi:10.1016/j.apacoust.2012.04.015.

Gerges, S.N.Y., and J .G. Casali. 2007. “Chapter 31.Hearing Protectors.” In Handbook of Noise and Vibration Control, 364-376. John Wiley \& Sons, Inc. Crocker, Malcolm $\mathrm{J}$.

Giguère, C., C. Laroche, V. Vaillancourt, and S.D. Soli. 2010. "Modelling Speech Intelligibility in the Noisy Work-Place for Normal-Hearing and Hearing-Impaired Listeners Using Hearing Protectors.” The International Journal of Acoustics and Vibration 15 (4): 156-167. doi:10.20855/ijav.2010.15.4268.

Gonçalves, C.G.O., D. Lüders, D.S. Guirado, E.J. Albizu, and J.M. Marques. 2015. "Perception of Hearing Protectors by Workers That Participate in Hearing Preservation Programs: A Preliminary Study.” CoDAS 27 (4): 309-318. doi:10.1590/2317-1782/20152014139.

Grenell, J.F. 1988. "Spectral Attenuation and Wearability of Circumaural Hearing Protectors as Influenced by Design Attributes and Work-Related Activity, Unpublished M.Sc Thesis, Virginia Polytechnic Institute and State University, Blacksburg, Virginia.” Thesis, Virginia Tech. https://vtechworks.lib.vt.edu/handle/10919/42343.

Groenewold, M. R., E. A. Masterson, C. L. Themann, and R. R. Davis. 2014. "Do Hearing Protectors Protect Hearing?” American Journal of Industrial Medicine 57 (9): 1001-1010. doi:10.1002/ajim.22323.

Hong, O., D. L. Chin, and D. L. Ronis. 2013. "Predictors of Hearing Protection Behavior Among Firefighters in the United States.” International Journal of Behavioral Medicine 20 (1): 121-130. doi:10.1007/s12529-011-9207-0.

Hong, O., S. L. Lusk, and D. L. Ronis. 2005. "Ethnic Differences in Predictors of Hearing Protection Behavior between Black and White Workers." Research and Theory for Nursing Practice 19 (1): 63-76.

Hsu, Yeh-Liang, Chung-Cheng Huang, Chin-Yu Yo, Chiou-Jong Chen, and Chun-Ming Lien. 2004. “Comfort Evaluation of Hearing Protection.” International Journal of Industrial Ergonomics 33 (6): 543-551. doi:10.1016/j.ergon.2004.01.001.

Ivarsson, A., N. G. Toremalm, and P. Brühl. 1990. "Eczema, Itching, Heat and Humidity Problems-Impediments to the Effective Use of Hearing Protectors.” In Proceedings of Internoise 1990, 90:1093-1096. Göteborg, Sweden: Institute of Noise Control Engineering.

Ivergard, T. B., and A. G. Nicholl. 1976. "User Tests of Ear Defenders.” American Industrial Hygiene Association Journal 37 (3): 139-142.

Ivergård, T.B.K., and A.G. McK. Nicholl. 1976. "User Tests of Ear Defenders.” American Industrial Hygiene Association Journal 37 (3): 139-142.

Killion, M.C. 2012. "Factors Influencing Use of Hearing Protection by Trumpet Players.” Trends in Amplification 16 (3): 173-178.

Killion, M.C., L.A. Wilber, and G.I Gudmundsen. 1988. “Zwislocki Was Right...” Hearing Instruments 39 (1): 14-18. 
Kochkin, S. 2000. "MarkeTrak V:" Why My Hearing Aids Are in the Drawer": The Consumers’ Perspective.” The Hearing Journal 53 (2): 34-36.

Kolcaba, K.Y., and R.J. Kolcaba. 1991. “An Analysis of the Concept of Comfort.” Journal of Advanced Nursing 16 (11): 1301-1310. doi:10.1111/j.13652648.1991.tb01558.x.

Kuijt-Evers, L.F.M, L Groenesteijn, M.P de Looze, and P Vink. 2004. "Identifying Factors of Comfort in Using Hand Tools.” Applied Ergonomics 35 (5): 453-458. doi:10.1016/j.apergo.2004.04.001.

Kushnir, T., L. Avin, A. Neck, A. Sviatochevski, S. Polak, and C. Peretz. 2006. "Dysfunctional Thinking Patterns and Immigration Status as Predictors of Hearing Protection Device Usage.” Annals of Behavioral Medicine 32 (2): 162-167.

Kusy, A. 1991. "Efficacité et Confort Des Protecteurs Individuels Contre Le Bruit: Résultats de La 4ieme Campagne d'essai.” Travail et Sécurité.

Kusy, A. 1996. The Efficiency and Comfort of Personal Protectors for the Control of Noise (in French). D (Stds. and Documents) ED 749. Paris, France: Institut National de Recherche et de Securite.

Laitinen, H., and T. Poulsen. 2008. “Questionnaire Investigation of Musicians' Use of Hearing Protectors, Self Reported Hearing Disorders, and Their Experience of Their Working Environment.” International Journal of Audiology 47 (4): 160-168. doi:10.1080/14992020801886770.

Lhuede, E. P. 1980. “Ear Muff Acceptance among Sawmill Workers.” Ergonomics 23 (12): 1161-1172. doi:10.1080/00140138008924823.

Lusk, S. L., D. L. Ronis, and M. M. Hogan. 1997. “Test of the Health Promotion Model as a Causal Model of Construction Workers' Use of Hearing Protection.” Research in Nursing \& Health 20 (3): 183-194.

Lusk, S.L., M.J. Kerr, and S.A. Kauffman. 1998. "Use of Hearing Protection and Perceptions of Noise Exposure and Hearing Loss Among Construction Workers.” American Industrial Hygiene Association Journal 59 (7): 466-470. doi:10.1080/15428119891010217.

Lusk, S.L., D.L. Roms, M.J. Kerr, and J.R. Atwood. 1994. “Test of the Health Promotion Model as a Causal Model of Workers' Use of Hearing Protection.” Nursing Research 43 (3): 151-157.

Mackenzie, K., G.G. Browning, and L.G. McClymont. 1989. "Relationship between Earmould Venting, Comfort and Feedback.” British Journal of Audiology 23 (4): 335-337. doi:10.3109/03005368909076522.

Mauney, D. W., and J. G. Casali. 1990. Preliminary Noise Attenuation Assessment of AICOMM's AIMic: Current Fitting Device Performance and Improved Ear Couplers. D (Stds. and Documents) Audio Lab No.2/14/90/2-HP; IEOR No. 9001. Blacksburg, VA: Auditory Systems Laboratory, Virginia Tech.

McCullagh, M.C., T. Banerjee, J.J. Yang, J. Bernick, S. Duffy, and R. Redman. 2016. "Gender Differences in Use of Hearing Protection Devices among Farm Operators." Noise and Health 18 (85): 368-375.

McCullagh, M.C., D.L. Ronis, and S.L. Lusk. 2010. "Predictors of Use of Hearing Protection among a Representative Sample of Farmers.” Research in Nursing \& Health 33 (6): 528-538. doi:10.1002/nur.20410. 
Melamed, S., S. Rabinowitz, M. Feiner, E. Weisberg, and J. Ribak. 1996. "Usefulness of the Protection Motivation Theory in Explaining Hearing Protection Device Use Among Male Industrial Workers.” Health Psychology 15 (3): 209-215. doi:10.1037/0278-6133.15.3.209.

Melamed, S., S. Rabinowitz, and M.S. Green. 1994. "Noise Exposure, Noise Annoyance, Use of Hearing Protection Devices and Distress among Blue-Collar Workers." Scandinavian Journal of Work, Environment \& Health 20 (4): 294-300.

Morata, T.C., A.C. Fiorini, F.M. Fischer, E.F. Krieg, L. Gozzoli, and S. Colacioppo. 2001. "Factors Affecting the Use of Hearing Protectors in a Population of Printing Workers.” Noise and Health 4 (13): 21-28.

Mozo, B.T., B.A. Murphy, and J.E. Ribera. 1995. User Acceptability and Comfort of the Communications Earplug (CEP) When Used in the UH-1 Helicopter,: Fort Belvoir, VA: Defense Technical Information Center. doi:10.21236/ADA294047.

Murphy, W.J., R.R. Davis, D.C. Byrne, and J.R. Francks. 2007. Advanced Hearing Protector Study Conducted at: General Motors Metal Fabricating Division Flint Metal Center - Flint, MI January 2004-February 2005. 312-11a. NIOSH.

Neitzel, R., and N. Seixas. 2005. "The Effectiveness of Hearing Protection Among Construction Workers." Journal of Occupational and Environmental Hygiene 2 (4): 227-238. doi:10.1080/15459620590932154.

Nordin, N. 1968. Hearing Testing. Stockolm, Sweden.

Norris, J., R. Chambers, N. Kattamis, B. Davis, and J. Bieszczad. 2011. "Effects of Custom Earplug Design Parameters on Achieved Attenuation." In Annual Meeting of the National Hearing Conservation Association. New Orleans, LA.

Park, M. -Y., and J. G. Casali. 1991. "An Empirical Study of Comfort Afforded by Various Hearing Protection Devices: Laboratory versus Field Results.” Applied Acoustics 34 (3): 151-179.

Park, M. -Y., and J. G. Casali. 1992. "More about Hearing Protector Comfort Ratings.” Applied Acoustics 35 (4): 335-337.

Patel, D.S., K. Witte, C. Zuckerman, L. Murray-Johnson, V. Orrego, A.M. Maxfield, S. Meadows-Hogan, J. Tisdale, and E. D. Thimons. 2001. "Understanding Barriers to Preventive Health Actions for Occupational Noise-Induced Hearing Loss.” Journal of Health Communication 6 (2): 155-168. doi:10.1080/10810730120042.

Pearson, E.J.M. 2009. “Comfort and Its Measurement - A Literature Review.” Disability and Rehabilitation: Assistive Technology 4 (5): 301-310. doi:10.1080/17483100902980950.

Reddy, R.K., P. Thorne, D. Welch, and S. Ameratunga. 2012. "Hearing Protection Use in Manufacturing Workers: A Qualitative Study.” Noise and Health 14 (59): 202-209. doi:10.4103/1463-1741.99896.

Ribera, J. E., B.T. Mozo, K.T. Mason, and B.A. Murphy. 1995. Communication and Noise IHazard Survey of CH-47D Crewmembers. 96-02. Fort Rucker, Alabama: U.S. Army Aeromedical Research Laboratory.

Samelli, A.G., R.F. Gomes, T.V. Chammas, B.G. Silva, R.R. Moreira, and A.C. Fiorini. 2018. "The Study of Attenuation Levels and the Comfort of Earplugs." Noise and Health 20 (94): 112-119. doi:10.4103/nah.NAH_50_17. 
Santoni, C.B., and A.C. Fiorini. 2010. "Pop-Rock Musicians: Assessment of Their Satisfaction Provided by Hearing Protectors." Brazilian Journal of Otorhinolaryngology 76 (4): 454-461.

Schulz, G., K. Rublack, A. Meister, S. Dybowski, K. H. Dubrau, and D. Gretzschel. 1983. "Comparative Studies of Insulating Effect and the Wearing Properties of Hearing Protector Means at the Place of Employment.” Z Gesamte Hyg Ihre Grenzgeb 29: 93-98.

Seixas, N.S., R. Neitzel, B. Stover, L. Sheppard, B. Daniell, J. Edelson, and H. Meischke. 2011. "A Multi-Component Intervention to Promote Hearing Protector Use among Construction Workers.” International Journal of Audiology 50 (sup1): S46-S56. doi:10.3109/14992027.2010.525754.

Smith, P.S., B.A. Monaco, and S.L. Lusk. 2014. "Attitudes toward Use of Hearing Protection Devices and Effects of an Intervention on Fit-Testing Results." Workplace Health \& Safety 62 (12): 491-499. doi:10.3928/21650799-2014090201.

Spomer, J., C.G. Estrich, D. Halpin, R.D. Lipman, and M.W.B. Araujo. 2017. “Clinician Perceptions of 4 Hearing Protection Devices.” JDR Clinical \& Translational Research 2 (4): 363-369. doi:10.1177/2380084417715599.

Stephenson, C.M., and M.R. Stephenson. 2011. "Hearing Loss Prevention for Carpenters: Part 1 - Using Health Communication and Health Promotion Models to Develop Training That Works.” Noise and Health 13 (51): 113-121. doi:10.4103/14631741.77207.

Stephenson, M.R. 2009. "Hearing Protection in the 21st Century: They're Not Your Father's Earplugs Anymore.” Seminars in Hearing 30 (01): 56-64.

Stephenson, M.R., P. B. Shaw, C.M. Stephenson, and P. S. Graydon. 2011. "Hearing Loss Prevention for Carpenters: Part 2 - Demonstration Projects Using Individualized and Group Training.” Noise and Health 13 (51): 122-131. doi:10.4103/14631741.77213.

Stork, R.L, and D.C. Gasaway. 1977. Evaluation of V-51R and EAR (Tm) Earplugs for Use in Flight. SAM-TR-77-1. Brooks Air Force Base. Texas: USAF School of Aerospace Medicine, Aerospace Medical Division.

Svensson, E.B., T.C. Morata, P. Nylén, E. F. Krieg, and A.-C. Johnson. 2004. "Beliefs and Attitudes among Swedish Workers Regarding the Risk of Hearing Loss." International Journal of Audiology 43 (10): 585-593. doi:10.1080/14992020400050075.

Sviech, P.S., C.G.O. Gonçalves, T.C. Morata, and J.M. Marques. 2013. “The Evaluation of Comfort of the Personal Hearing Protection Devices as an Intervention for Hearing Loss Prevention.” Revista CEFAC 15 (5): 1325-1337. doi:10.1590/S151618462013005000018.

Sweetland, K.F. 1983. "Physical Predictors for Earmuff Comfort, Master's Thesis, Loughborough University of Technology, Loughborough, United Kingdom.” Master's thesis, Loughborough University of Technology. https://dspace.lboro.ac.uk/dspace-jspui/handle/2134/12214. 
Tak, S.W., R. R. Davis, and G.M. Calvert. 2009. "Exposure to Hazardous Workplace Noise and Use of Hearing Protection Devices among US Workers-NHANES, 1999-2004.” American Journal of Industrial Medicine 52 (5): 358-371. doi:10.1002/ajim.20690.

Tantranont, K., and N. Codchanak. 2017. "Predictors of Hearing Protection Use among Industrial Workers.” Workplace Health \& Safety 65 (8): 365-371.

Terroir, J., O. Doutres, and F. Sgard. 2017. “Towards a 'Global' Definition of the Comfort of Earplugs.” In Proceedings of Inter-Noise, 255:108-114. Hong-Kong, China.

Tisserand, M., and G. Krawsky. 1972. Comfort Evaluation of Individual Hearing Protectors. 010/RE/A. Vandoeuvre, France: Natl. Inst. Res. Safety.

Tourigny, P. 1980. “Les Facteurs Influencant Le Port Des Protecteurs Auditifs sans Trois Industries Du Meuble de La Region de Laurier-Station Au Quebec (in French), Master’s Thesis, Université Laval, Québec, Canada.” Québec, Canada: Université Laval.

Tufts, J.B., S. Chen, and L. Marshall. 2013. “Attenuation as a Function of the Canal Length of Custom-Molded Earplugs: A Pilot Study.” The Journal of the Acoustical Society of America 133 (6): EL446-EL451. doi:10.1121/1.4802896.

Tufts, J.B., M.A. Hamilton, A.J. Ucci, and J. Rubas. 2011. "Evaluation by Industrial Workers of Passive and Level-Dependent Hearing Protection Devices.” Noise and Health 13 (50): 26-36. doi:10.4103/1463-1741.73998.

Wheeler, D. E., and Aram Glorig. 1956. "The Industrial Hygienist and Ear Protection.” Noise Control 2 (1): 45-72. doi:10.1121/1.2369177.

Yu, J.-F., K.-C. Lee, R.-H. Wang, Y.-S. Chen, C.-C. Fan, Ying-Chin Peng, Tsung-Hsien Tu, Ching-I. Chen, and Kuei-Yi Lin. 2015. "Anthropometry of External Auditory Canal by Non-Contactable Measurement.” Applied Ergonomics 50 (September): 50-55. doi:10.1016/j.apergo.2015.01.008.

Zwislocki, J. 1958. "Ear Protection: Effectiveness vs. Comfort.” Noise Control 4: 14-15. 